\title{
Kurthia Sp, a Novel Member of Phosphate Solubilising Bacteria from Rhizospheric Tea Soil of Darjeeling Hills, India
}

\author{
${ }^{1}$ Binod Chandra Sharma, ${ }^{2}$ Rashi Subba, ${ }^{3}$ Aniruddha Saha \\ ${ }^{1,2}$ P.G. Department of Botany, Darjeeling Government College, Darjeeling -734101, India \\ ${ }^{3}$ Department of Botany, University of North Bengal, Raja Rammohanpur, Dt. Darjeeling, India
}

\begin{abstract}
Rhizospheric soil from tea [Camellia sinensis (L.) Kuntze] bushes of Darjeeling hills was screened for the presence of phosphate solubilising bacterial populations on Pikovskayas agar. One of the potent strains was identified as Kurthia sp. In vitro tricalcium phosphate solubilising ability of this strain was determined as $40.62 \pm 1.1 \mathrm{mg} / \mathrm{l}$ with a drop in $\mathrm{pH}$ from 7.0 to 5.60 indicating the importance of acid production in the solubilisation process. This strain also produced growth regulating substance (IAA) under in-vitro conditions in the presence of precursor tryptophan. The amount of IAA released was $17.5 \mathrm{mg} / \mathrm{l}$. This genus is considered as new novel member as phosphate solubilisers which may be developed as phosphatic biofertilizers after further characterisation in field conditions.
\end{abstract}

Key-Words: Darjeeling tea, rhizosphere, Kurthia sp., phosphate solubilisation

\section{Introduction}

After nitrogen phosphorus $(\mathrm{P})$ is the major plant growth-limiting nutrient despite being abundant in soils in both inorganic and organic forms. However, many soils throughout the world are P-deficient because the free phosphorus concentration (the form available to plants) even in fertile soil is generally not higher than 10 $\mu \mathrm{M}$ even at $\mathrm{pH} 6.5$ where it is most soluble [1].

Phosphate solubilizing microorganisms (PSMs) is an ecologically special functioning group of soil microorganisms which play an important role in the turnover of organic $\mathrm{P}$ and insoluble inorganic phosphate, and in the cycling of $\mathrm{P}$ in soil $[2,3]$. The composition and dynamics of this functional group was influenced greatly by vegetation type, soil texture, soil chemical elements, and $\mathrm{pH}$ in soil solution $[4,5,6,7]$.

PSMs convert these insoluble phosphates into soluble forms through the process of acidification, chelation, exchange reactions and production of gluconic acid [8].

Phosphate solubilising bacteria (PSB) produce amino acids, vitamins and growth promoting substances $[9,10]$ which promote plant growth. Although the mechanisms by which plant growth promoting rhizobacteria (PGPR) promote plant growth are not yet fully understood, many different traits of these bacteria are responsible for growth promotion activities [11]. It includes the ability to produce or change the concentration of the plant hormones indole acetic acid (IAA), gibberellic acid, cytokinins, and ethylene; fix dinitrogen; suppress the growth of deleterious microorganisms by production of siderophore, $\beta-1,3$-glucanase, chitinases, antibiotics, and cyanide; and dissoIve phosphates and other nutrients.

IAA produced by bacteria improves plant growth by increasing the number of root hairs and lateral roots [12]. Microbial biosynthesis of IAA in soil is enhanced by tryptophan from root exudates or decaying cells $[13,14]$. Tea is regarded as an important plantation crop of very high economic and commercial value in NorthEastern India. The studies on physico-chemical and microbiological soil properties under tea plantation crop are scanty [15]. Therefore the objectives of our research were to isolate the phosphate solubilizing bacteria from the rhizosphere of tea plants, further screen them for their performance under in vitro conditions.

\subsection{Isolation of phosphate solubilizing bacteria}

Materials and Methods

Rhizospheric soil from healthy tea (Camellia sinensis (L.) Kuntze ) bushes of Singla Tea Estate, Darjeeling was collected and studied in the laboratory. Ten gram $(10 \mathrm{~g})$ of soil sample was suspended in $90 \mathrm{ml}$ of sterile distilled water serial dilutions were prepared until the $10^{-7}$ dilution was obtained. The Pikovskaya agar ( $10 \mathrm{~g}$ Glucose, $5 \mathrm{~g}$ tricalcium phosphate, $0.5 \mathrm{~g}$ ammonium sulphate, $0.2 \mathrm{~g}$ potassium sulphate, $0.1 \mathrm{~g}$ magnesium sulphate, $0.5 \mathrm{~g}$ yeast extract, trace amount of manganese sulphate and ferrous sulphate, $20 \mathrm{~g}$ agar, $1000 \mathrm{ml}$ distilled water, $\mathrm{pH}: 6.8$ ) medium was used for isolation and maintenance of PSB. Bacterial colonies causing clear phosphate solubilizing zones by a turbid white background were selected and purified for further study. The colony diameter of PSB colony (halo zones) was measured by using metric scale. PSB isolates were preliminarily identified based on the morphological tests such as motility, cell shape and size and biochemical tests such as glucose fermentation, urea hydrolysis, nitrate reduction, citrate utilization, indole production, 
Kurthia sp, a novel member of phosphate solubilising bacteria from rhizospheric tea soil of

Voges-proskaeur and methyl-red reaction and a potent isolate was sent to type culture collection for identification [16].

\subsection{Quantification of $P$ solubilization}

The phosphorus solubilizing potential of selected PSB strain was tested in vitro by estimating available phosphorus in the Pikovskaya's broth amended with known amount of tricalcium phosphate as a substrate. A control without any inoculation was also maintained. The organisms were allowed to grow for 7 days at $30^{\circ} \mathrm{C}$ and centrifuged at 10,000 rpm for $10 \mathrm{~min}$ in a cooling centrifuge (REMI-C30BL, Remi, India). Phosphorus was determined in supernatant following the procedure of Fiske and Subbarow[17] using UV-VIS Spectrophotometer (SHIMADJU UV-1700 Pharmaspec, Shimadju, Japan).

\subsection{Measurement of $\mathrm{pH}$}

A change in $\mathrm{pH}$ of the medium due to the growth of PSB was measured with a digital $\mathrm{pH}$ meter (Elico, India) after 7 days of incubation.

\subsection{IAA Production}

The production of IAA was determined following the standard protocol [18]. The tested bacterial strains was grown in LC medium in the presence of tryptophan $(100 \mu \mathrm{g} / \mathrm{l})$ and incubated at $30^{\circ} \mathrm{C}$ for 3 days. A two $\mathrm{ml}$ culture was removed from each tube and centrifuged at $10,000 \mathrm{rpm}$ for 15 minutes. One $\mathrm{ml}$ of supernatant fluid was transferred to fresh tube to which $100 \mu \mathrm{l}$ of $10 \mathrm{mM}$ orthophosphoric acid and $2 \mathrm{ml}$ of reagent consisting of $1 \mathrm{ml}$ of $0.5 \mathrm{FeCl}_{3}$ in $50 \mathrm{ml}$ of $35 \% \mathrm{HClO}_{4}$ were added. The absorbance of the developed pink colour was read at $530 \mathrm{~nm}$ after $25 \mathrm{~min}$ in UV-Vis Spectrophotometer (SHIMADJU UV-1700 Pharmaspec, Shimadju, Japan). the IAA concentration in the culture was determined by using a calibration curve of pure IAA as a standard, following linear regression analysis [18].

\section{Results}

One of the colonies which produced halo around it on the Pikovskaya agar was selected for characterisation and designated as GCS1.

Table 1 summarizes the values of $\mathrm{P}(\mathrm{mg} / \mathrm{l})$ solubilised in liquid culture and the change in $\mathrm{pH}$ of the corresponding medium after seven days of incubation as well as the IAA production in vitro after 3 days of incubation in presence of tryptophan.

Table 1: In vitro phosphate solubilisation and IAA production by PSB strain GCS1

\begin{tabular}{|l|l|l|l|}
\hline $\begin{array}{l}\text { PSB } \\
\text { Strain } \\
\text { (GCS1) }\end{array}$ & $\mathrm{pH}$ & $\begin{array}{l}\text { Available phosphorus } \\
\text { (mg/l) after 7 days of } \\
\text { incubation }\end{array}$ & $\begin{array}{l}\text { IAA production } \\
\text { (mg/l) after 3 days } \\
\text { of incubation }\end{array}$ \\
\hline $\begin{array}{l}\text { Kurthia } \\
\text { sp. }\end{array}$ & 5.60 & $40.62 \pm 1.1$ & 17.5 \\
\hline
\end{tabular}

Phosphate solubilisation was accompanied by a decrease in the $\mathrm{pH}$ of the medium by the selected isolate DTS02. Amount of available phosphate was determined as $40.62 \pm 1.1 \mathrm{mg} / \mathrm{l}$ from $0.5 \%$ tricalcium phosphate with decrease in $\mathrm{pH}$ from an initial value of 6.8 to 5.60 after 7 days of incubation.

Table 2: Biochemical characteristics of PSB strain GCS1

\begin{tabular}{|l|c|}
\hline Biochemical characteristics & Results \\
\hline Gram's reaction & + \\
\hline Methyl-red test & + \\
\hline Voges-Proskaeur & + \\
\hline Citrate Utilization & + \\
\hline Nitrate reduction & + \\
\hline Catalase test & + \\
\hline Arginine dihydrolase & + \\
\hline Xylose & + \\
\hline Dextrose & + \\
\hline Galactose & + \\
\hline Mannose & + \\
\hline Indole test & - \\
\hline $\mathrm{H}_{2} S$ production & - \\
\hline Urea test & - \\
\hline Gas production from glucose. & - \\
\hline
\end{tabular}


The amount of IAA produced was found to be $17.5 \mathrm{mg} / \mathrm{l}$ by this isolate after 3 days of incubation. Eight PSB strains isolated also from tea rhizospheric soil produced IAA in the range of 10-30 mg/l as reported earlier[19].The biochemical characterization of the PSB isolate (Table 2) showed that it was gram positive, rod shaped and positive for methyl red, voges-proskaeur, citrate utilization, nitrate, catalase, arginine dihydrolase, xylose, dextrose, galactose, mannose and was negative for indole production, $\mathrm{H}_{2} \mathrm{~S}$ production, starch hydrolysis, urea hydrolysis and gas production from glucose. The isolate GCS1 was sent to IMTECH, Chandigarh, India and identified as Kurthia sp.

\section{Discussion}

The results obtained in this study throw light on the existence of phosphate solubilizing bacteria in rhizosphere soils of tea plants. Baby et. al., [20] carried out an investigation on microbial dynamics in the rhizosphere of tea plants and reported that there was a significant difference on the population level of PSB in different clones/seedlings of tea. Further, they reported that the population of nitrogen fixing Azospirillum and PSB were higher in young tea fields than older fields.

In general, Ca-phosphate solubilisation seems to be link with $\mathrm{pH}$ decrease of the medium but this $\mathrm{pH}$ decrease was not strictly proportional to the amount of the phosphate solubilised. During present study, it was found that there is slight correlation between the decrease of $\mathrm{pH}$ and the phosphate solubilised. These findings were supported by the reports of [21] who reported that sometimes the culture filtrate $\mathrm{pH}$ was relatively high and yet in the medium high $\mathrm{P}$ solubilization occurred, this may occur due to the chelation of organic acids with $\mathrm{Ca}^{++}$ion in tricalcium phosphate.

Similarly, it has been reported [22, 23, 24] that $\mathrm{pH}$ had no affect on $\mathrm{P}$ solubilization [25] also found no correlation between the $\mathrm{pH}$ and solubilization of $\mathrm{P}$ over an incubation period of 7 days. Similar observation was reported with $P$. aurantiogriseum [21], with a Penicillium isolate [26] and with P. radicum [24].

The $\mathrm{pH}$ drop in PSM liquid cultures have been reported in several researches which supports the $\mathrm{pH}$ change in present study [27, 28, 29, 30].

Bacteria isolated from rhizosphere soils are known to produce growth-promoting substances [31] and some of them are capable of dissolving phosphate [32]. Phosphate solubilising bacteria are capable of producing physiologically active auxins that may have pronounced effects on plant growth. The cultures release greater quantities of IAA in the presence of a physiological precursor, tryptophan, in a culture medium. Production of IAA varies greatly among different species and is also influenced by culture conditions, growth stage and availability of substrate(s) [31, 33].

The amount of IAA produced by this isolate was higher than one reported earlier [34] which range from 2.31 to $9.43 \mu \mathrm{mol} / \mathrm{ml}$ and was lower than that have been reported by [35] which range from 34.02 to 45.31 $\mathrm{mg} / \mathrm{l}$. The amount of IAA biosynthesis by the novel strain of Kurthia sp. is found to be considerably higher than reported Bacillus isolates which ranged from 2.04 to $2.78 \mathrm{mg} / \mathrm{l}$ [36].

\section{Conclusion}

In conclusion, results of this study have shown that Kurthia sp. which was isolated from tea garden of Darjeeling hills are capable of producing plant growth promoting substance IAA, capable of solubilizing inorganic phosphates thereby decreasing the $\mathrm{pH}$ of the medium. Further studies are required to evaluate the phosphate solubilising efficiency of this strain in vivo. This strain may further be characterized to use as a potential novel biofertilizer in organic farming.

\section{Acknowledgements}

We are grateful to Department of Science and Technology, Govt. of India for providing instrumentation facilities to the PG Dept. of Botany, DGC in the form of DST-FIST scheme. RS is grateful to UGC for providing financial assistance to her under Rajiv Gandhi National Fellowship Scheme.

\section{References}

[1] P. Gyaneshwar, G.N. Kumar, L.J. Paresh and P.S. Pole, Role of soil micro-organisms in improving P nutritions of plants. Plant Soil,2002, 245, 83-93.

[2] F.J. Stevenson, Cycles of Sol Carbon, Nitrogen, Phosphorus, Sulphur, Micronutrients (Wiley and Sons Inc, New York 1986)

[3] J.L. Smith, E.A. Paul, The significance of soil microbial biomass estimations. In Bollag, J.M., Stozky, G., Eds. Soil Biochemistry, (Marcel Dekker, Inc., New York, 1990) 6: 359-396.

[4] E.A. Curl, D.F. Bonner and B.R. Sabey, The Rhizosphere. (Berlin, Spinger-Verlag, 1986), 167-175.

[5] R.M.N. Kucey, Phosphate-solubilizing bacteria and fungi in various cultivated and virgin Alberta soils. Canadian Journal Soil Science, 1986, 63, 671-678

[6] Q.M. Lin, X.R. Zhao and Y. Sun, Community characters of soil phosphobacteria in four ecosystem. Soil and Environmental Sciences, 9(1), 2000, 34-37 (in Chinese, with English abstract).

[7] Y. Ruling, Phosphate solubilizing microorganisms in upland of China. Chinese Journal of Soil, 1988, 20(5), 243-246 (in Chinese). 
[8] H.M. Chung, M. Park, S. Madhaiyan, J. Seshadri, H. Song Cho and T. Sa, Isolation and characteirzation of phosphate solunbilizing bacteria from the rhizosphere of crop plants of Korea, Soil BIol. Biochem, 2005, 37, 1970-1974.

[9] J. Gonzalez, V. Salmeron, J. Moreno and A.R. Cornmenzana, Amino acids and vitamins produced by Azotobacter vinelandii ATCC 12837 in chemically-defined media and dialyzed soil media. Soil Biol Biochem, 1983, 15, 711-713.

[10] W. Zimmer, K. Roeben and H. Bothe, An alternative explanation for plant promotion by bacteria of the genus Azospirillum, Plant and Soil, 1988, 176, 333-342.

[11] A.J. Cattelan, P.G. Hartel and J.J. Fuhrmann, Screening for plant growth-promoting rhizobacteria to promote early soybean growth, Soil Sci. Soc. Am. J., 1999, 63, 1670-1680.

[12] Y. Okon and Y. Kapulnik, Development and function of Azospirillum-inoculated roots, Plant and Soil,1986, 3-16.

[13] W.T. Frankenberger Jr and M. Arshad, Microbial production of plant growth regulating substances in soil. P. 162-171. In C. Keel, B. Koller and G. Defago (Eds.) Plant Growth-Promoting Rhizobacteria, Progress and Prospects. The Second International Workshop on PGPR. Interlaken, Switzerland.

[14] E. Benizri, A. Courtade, C. Picard and A. Guckert, Role of maize root exudates in the production of auxins by Pseudomonas fluorescens M.3.1: Short communication. Soil Biol Biochem, 1998, 30, 1481-1484.

[15] K.C.Wilson and M.N. Clifford, Tea cultivation to consumption, (Chapman and Hall, London1992).

[16] N. Kannan, Laboratory Manual in General Microbiology (Panima Publishing Corporation, New Delhi, India, 2002)

[17] C.H. Fiske and Y Subbarow, Colorimetric determination of phosphorus, J Biol Chem 1925, 66, 375-400.

[18] N. Bano and J. Mussarat, Characterization of a new Pseudomonas aeruginosa strain NJ-15 as a potential biocontrol agent. Curr Microbiol, 2003, 46,324-328.

[19] B. C. Sharma, R. Subba and A. Saha, In-vitro solubilization of tricalcium phosphate and production of IAA by phosphate solubilizing bacteria isolated from tea rhizosphere of Darjeeling Himalaya, Plant Sciences Feed, 2012, 2(6), 96-99.

[20] U.I. Baby, B.N. Tensingh, P. Ponmurugan and R. Premkumar, Population dynamics of nitrogen fixing and phosphate solubilizing bacteria in tea soil, UPASI Tea Res Found Newsletter, 2001, 10(2), 4

[21] P. Illmer and F. Schinner, Solubilisation of inorganic calcium phosphate - solubilising mechanisms, Soil Biol Biochem 1992a, 27, 257-263.

[22] P.E.A. Asea, R.M.N. Kucey and J.W.B. Stewart, Inorganic phosphate solubilization by two Penicillum species in solution culture and soil, Soil Biol Biochem, 1988,20, 459-464.

[23] H.M. Salih, A.I. Yahya, A. Abdul-Rehman and B.H. Munam, Availability of phosphorus in a calcareous soil treated with rock phosphate or super-phosphate or affected by phosphate dissolving fungi. Plant Soil 1989, 20, 181-185.

[24] M.A. Whitelaw, T.J. Harden and K.R. Helyar, Phosphate Solubilization in solution culture by the soil fungus Penicillum radicum, Soil Biol Biochem, 1999, 32, 655-665.

[25] V. Narsian, J. Takkar and H.H. Patel. Mineral phosphate solubilization by Aspergillus aculeatus. Indian J Exp Biol, 1995, 33:91-91.

[26] D.H. Goenadi and R. Saraswati, Phosphate solubilizing capabilities of selected phosphate solubilizing fungal isolates. Menara Perkebunan, 1993, 61,61-66.

[27] J.E. Cunningham J.E. and C. Kuiack, Production of citric and oxalic acids and solubilisation of calcium phosphate by Penicillium bilaii. Appl Environ Microbiol,1992, 58,1451-1458.

[28] M.R. Motsara, P.B. Bhattacharya, B. Srivastava, Biofertilizers: their Description and Characteristics. In: Biofertilizer Technology, Marketing and Usage, A Sourcebook-cum-Glossary. (Fertilizer development and consultation organization, 204-204A Bhanot Corner, 1-2 Pamposh Enclave, New Delhi, 110048, India, 1995) 9-18.

[29] P. Illmer, A. Barbato and F. Schinner, Solubilization of hardly soluble $\mathrm{AlPO}_{4}$ with P-solubilizing microorganisms, Soil Biol Biochem $1995,27,260-270$.

[30] B. Bar-Yosef, R.D. Rogers, J.H. Wolfrm and E. Richman, Pseudomonas cepacia mediated rock phosphate solubilization in kaolinite and montmorillonite suspensions, Soil Science Society of America, 1999, 63,1703-1708.

[31] M.E. Brown, Plant growth substances produced by microorganism of soil and rhizosphere, J Appl Bacteriol, 1972, $35,443$.

[32] J.M. Barea, J.A. Ocampo, R. Azcon, J. Olivares and E. Montoya, Effect of ecological factors on the establishment of Azotobacter in the rhizosphere, Ecological Bulletin (Stockholm), 1978, 26,325-330.

[33] K. Vijila, Estimation of IAA production in nitrogen fixing microorganisms. Practical manual-microbial interaction in soil, (Tamil Nadu Agricultural University, Coimbatore, 2000), 38-39.

[34] J.R. De Freitas, M.R. Banerjee and J.J. Germida, Phosphate-solubilizing rhizobacteria enhance the growth and yield but not phosphorus uptake of canola (Brassica napus L.). Biol Fertil Soils, 1997, 24, 358-364.

[35] P. Ponmurugan and C. Gopi, In vitro production of growth regulators and phosphatase activity by phosphate solubilizing bacteria. Afr J Biotech, 2006, 5(4), 348-350

[36] M.A. Qureshi, Z.A. Ahmad, N. Akhtar, A. Iqbal, F. Mujeeb and M.A. Shakir, Role of Phosphate solubilising Bacteria (PSB) in enhancing P availability and promoting cotton growth. The Journal of Animal and Plant Sciences, 2012, 22(1), 204-210. 